\title{
A Project of Link between University and Business
}

\author{
Carmen de Pablos \& Mónica de Pablos \\ Rey Juan Carlos University, Madrid, Spain
}

\section{carmen.depablos@urjc.es mdepablos@trucco.es}

\begin{abstract}
The present project "Technological diagnosis for Firms" offers a practical experience for the transfer pf knowledge between the university and business firms. It implies an agreement between the University and a group of firms operating near the University locations. The main objective of this project is to develop business consultancy in a group of 15 firms established in the south of Madrid, next to the University Campus. The project has been implemented by researchers from the Business Administration Area in the Rey Juan Carlos University in Madrid, Spain. There have been fifteen participant firms. 6 teams of researchers formed by 2, 3, or 4 different members have developed the work. A group of diagnosis and propositions of improvement have been realised in the mentioned group of firms. Different methodologies of strategic and organisational analysis have been used.
\end{abstract}

Key words: centre for technological transfer, researchers, synergies

\section{Introduction}

The economy of innovation teaches us how the rhythms and examples of technological innovation differ in different industries. Amongst the main explanations coming from the economic theory to find out about these differences, we can stress the ones related with the different sources of technological progress (Winter, 1984; Dosi et al., 1995) and those situated in the origin of the innovative diversity amongst different industries in the different phases of the "life cycle" of firms operating in different industries (Utterback \& Abernathy, 1975; Klepper, 1996).

The technological dimension of the innovation is acquiring a crucial importance (Cobbenhagen, 2000). Results in different projects that try to measure the concept of intellectual capital in the European Union, as for example the MERITUM and the E-Know-Net Projects, are showing how the management of the intellectual capital is, especially for big firms an internal problem (Bukh, 2003). However for the SMEs firms, where the financial and human resources are scarce, the proper management of the intellectual capital implies an effective use of external relationships. The interaction of SMEs with their environment (in the framework of their industry or territory systems of innovation), the stimulus they receive from other Institutions (business associations, technological centres, policy makers, competitors, etc.) are of crucial importance when they try to

Material published as part of this publication, either on-line or in print, is copyrighted by the Informing Science Institute. Permission to make digital or paper copy of part or all of these works for personal or classroom use is granted without fee provided that the copies are not made or distributed for profit or commercial advantage AND that copies 1) bear this notice in full and 2) give the full citation on the first page. It is permissible to abstract these works so long as credit is given. To copy in all other cases or to republish or to post on a server or to redistribute to lists requires specific permission and payment of a fee. Contact Publisher@InformingScience.org to request redistribution permission. increase their resources and the efficient use of them (Chaminade 2002).

The interface units can be very important to support SMEs to achieve an effectiveness management of their non technological resources.

Johanson et al. (2001) show how the most innovative firms are those that invest in intangible actives and develop organisational routines that allow a bet- 
ter management of resources in a systematic way.

The conceptual framework of the Systems of Innovation is born to front the need to study the processes of innovation as processes of interactive learning where some non technological factors such as the establishment of networks of collaboration of human capital flows are key elements. It is important to stress the lack of connection between the research groups that study the intangibles and the intellectual capital as a factor of innovation and the ones oriented towards systems of innovation. One of the main objectives of this paper consists of finding bridges of connection between these two lines of analysis. They are quite linked in reality, if we consider their starting points but quite separated from the practical point of view.

The non-technology dimension of the innovation can be classified in three key elements: human capital, structural capital and relational capital. In a macroeconomic level we can assume how the non technological dimension of the process of innovation is reached through and analysis in the training and mobility of the human capital, the study of the networks and systems of innovation (relational capital) and the analysis of institutions (structural capital).

Of all these dimensions, we are going to study in detail some groups that have been specially less studied up to now: the researchers (human capital) and the SMEs (structural capital) and the regional systems of innovation (relational capital).

We are going to show a practical experience that we have just recently developed where the three dimensions have been applied in order to find an efficiency system for solving problems in SMEs operating in a certain local area.

\section{The Relationship Industry and Centres of Technological Transfer}

The relationships between university and industry have been increased in the last years in the area of Social Sciences. There has been an increase in the number of co-operations and agreements achieved.

The present project "Technological diagnosis for Firms" shows this reality of the need of connection between the university and business entities. It implies an agreement between the University via the CINTECC (Centre for Technological Transference) and a group of firms operating near the University locations.

The objective of this program is to fortify the relationship between these two Entities (University and Firms).

Both Institutions must be aware of the importance of having mutual benefits of co-operating if they want to be maintained in the era of knowledge.

The CINTECC as a bridge between university results and organisations pursue three main objectives,

1. A program of developing a consultancy program in firms

2. The evaluation of the firm's point of start and the elaboration of training plans in the organisation

3. The participation in projects of research and technological innovation

\section{The Project}

The main objective of this project is to develop business consultancy in a group of 15 firms operation in the south of Madrid, next to the University Campus. 
The project has been implemented by researchers from the Business Administration Area in the Rey Juan Carlos University in Madrid, Spain.

There have been fifteen participant firms. 6 teams of researchers formed by 2, 3, or 4 different members have developed the work. The teams are mixed. We have tried to make work together people with a typical research profile with people having previous or actual consultancy experience in firms.

A group of diagnosis and propositions of improvement have been realised in the mentioned group of firms. Different methodologies of strategic and organisational analysis have been used.

The realised diagnoses have been centred on the problems and feelings firms have asked for in each one of the teams. The final recommendations have mainly been oriented to,

- Rationalise, simplify and flexibly firms working processes and management procedures.

- Determine and distribute ways of working amongst people.

- Recommend organisational improvements and the use of information technologies in each case.

\section{Methodology of Work}

The work has been done by a group of researchers acting as consultants for each firm according to the following steps,

$\checkmark$ Preliminary study, the team has performed a preliminary study in order to identify through data analysis, surveys and interviews the main objectives and needs for technical assistance in the organisation. After that, different areas of interest to work in have been identified.

$\checkmark \quad$ Main field of work, a variety of business consultant methodologies have been used to analyse the situation of process to improve. Amongst the most frequent techniques used by the different groups in this phase, we can stress,

- The use of techniques for structured analysis. It will promote a better diagnosis of the processes and establish priorities for improving them (cost reductions, improvements in quality, reduction of the risk, and so on.).

- Services based in software, analysis of the existence and optimisation of integrated tools (ERPs, CRMs) and business intelligence

- The management of change, the application of methodologies to change certain situations (centred on the various dimensions of culture in the firm, organisational climate and human resource)

$\checkmark$ The work teams have elaborated a final report showing the diagnoses and the specific proposals for improvement for each firm. The report contains the realised diagnoses and the specific actions for the improvement of each of the evaluated areas and processes.

$\checkmark \quad$ In addition, in many cases a program of implementation of suggestions where measures to implement must be taken into account has been offered, apart from suggestions on responsibilities in the organisation, timetables and the surveillance in the process of change.

Table 1 shows the firms where the different working teams have developed the project, 
Table 1. The firms in the project

\begin{tabular}{|l|l|}
\hline Firm & Team group \\
\hline Técnica Normalizada (TMN) & 1 \\
\hline Inter. Muelle & 2 \\
\hline Tecnicas Aeronauticas Madrid & 3 \\
\hline Turbaflor, SL & 4 \\
\hline Siglo XX1 & 5 \\
\hline Administraciones Castillo & 6 \\
\hline PAL electricidad & 5 \\
\hline Comunicación Gráfica Alborada & $\mathbf{5}$ \\
\hline Tridente Image Builders & $\mathbf{3}$ \\
\hline Imasoto & $\mathbf{2}$ \\
\hline Veldis & $\mathbf{4}$ \\
\hline Utiplas & $\mathbf{1}$ \\
\hline Euroacademias & $\mathbf{6}$ \\
\hline Valverauto & $\mathbf{2}$ \\
\hline Hidrocombust & $\mathbf{3}$ \\
\hline & \\
\hline
\end{tabular}

\section{Main Findings}

Depending on the problems identified in the different firms analysed, the work groups have applied various techniques and methodologies for the diagnosis of the situation of the firms. In the following paragraphs we try to offer the main findings in each of the consultancies performed by the various groups. We mainly put a special emphasis on,

1. Description of the firm

2. Main problem

3. The group of research

4. Tools for analysis

5. The diagnosis realised

6. Main recommendations

Imasoto is a family firm. It produces pieces of furniture for firms, 37 employees are working for the firm. It operates through a standardised system in lots from 100 to 500 . The main problem for the company is to measure their competitive capacity when they compare with the main competence. The consultancy group has applied the SWOT analysis and has followed a Porter's five forces orientation too. In the diagnosis they have realised that they do not calculate financial indexes and their evolution in time. In the production processes, they calculate the costs of the products but they do not use them to optimise their production. As a consequence of the external analysis, there are important changes in the industry, in the way they offer and distribute their product. As main recommendations the consultancy group offer a strategy of specialisation in customers. For example, the implementation of a personalised service with segmentation of cus- 
tomers, an increase in the market share, a focus in new segments of users in the same geographic market and an increase the distribution circuits.

Veldis is an exclusive import and distribution channel of food products and drinks. They distribute a range of products going from traditional to innovative ones. 19 employees are working on the firm. They present a small size in comparison to the industry and are too much dependant on certain products and providers. An Analysis of the firm's functional areas and a SWOT analysis have been applied. We have found an excess in the logistic costs for their actual structure. They are very dependant in other firms for the outsourcing of the excessive distribution channel. They are informed to obtain more external information (from the Public Health, Government, Universities, etc.). A redesign is recommended to sustain a profitable rate of growth (they have increased in customer numbers without having into account proper organisational fits). They have been oriented to establish a policy of standardised ways of payment and purchasing and to use techniques of market research to segment customers and to develop a corporate web page in Spanish and English.

Siglo XXI. Their core competence is the prevention of labour risks in 4 different areas, 1 medical and 3 technical. 3 employees are working for the firm. They do not define any priority for the start of the consultancy work. They are looking for generic pieces of advice. Interviews are maintained with technical people in the firm and with the main shareholder too. There is a good labour climate, a clear assignment of tasks; they need to invest in IT to get better reports. They need to take care of the corporate image by promoting communication campaigns to search customers in a highly competitive industry. A better planning of the strategies for growth are needed and to study the possibility of offering the customers services in different close geographic areas To study the possibility of diversification in a related way, for example the audit in risk prevention. They need to ask for public budget and to promote the training for employees and to improve processes by implementing software programs to achieve a greater agility

Utiplas, S.L., They are specialised in the Metal industry. It is composed by 12 employees. They recognise as the main problem to promote a group of routines to go "from the fabric to the firm".

They need to know about the chemical composition of the wine plug. As a main tool for the analysis, interviews with the employees have been used. In the diagnosis realised they present an informal structure, the communication channels between employees work well. They present a lack of organisation in the placement of raw materials. As main recommendations, the consultancy group suggests to formalise at least the part of customer reception based only in the person who develops the queries. The implementation of ERP systems for accounts payable, stocks management, etc. is desirable. The organisation of the warehouse in final finished products and raw materials is needed. Time savings in the search of raw materials and in handling the final product are required. In order to know the chemical composition of the plug, it is recommended to contact with the centre for transfer of knowledge in the university

Euroacademias, they develop training programs for firms. They offer places and very modern pedagogical means. There are 50 employees working in 3 centres. 10 of them are performing administrative tasks. Their main problem refers to the option of growing. There is a lack of penetration in the number of students in the university system. A functional areas analysis, interviews with managers and surveys with employees have been applied as the main tools for analysis. In the diagnosis realised we have found that there is not a policy for planning the future growth as a consequence of organisational units. The firm does not offer a specific marketing plan. They do not know the markets where they can be driven to and they have been unable to offer a service for university students. As main recommendations, the consulting group has recommended to establish a strategic planning to design a strategy for growing containing at least a market study, to know about market share and attractiveness for focus on future customers and to promote a pub- 
licity plan to favourite their brand and to be known in other market segments (i.e. university students)

Intermuelle, S.L., is in the industry of manufacturing wharfs and springs 6 employees, a family business small series on demand. They present as a main problem an excessive dependency of a main customer in the development of the production technology. An analysis of the main functional areas and a SWOT analysis have been the main tools for the analysis. In the diagnosis realised we have realised that they do not have a special control on the economic financial issues. They lack of a deep knowledge about their competitors and besides they have an excess of dependency in the relationships with some firms. As a main suggestion we have recommended to develop an analysis of the competence to find out more about customers and know more about the main characteristics from other big firms. To search for "good relations", with firms that are competitors and customers at the same time To calculate some economic indexes and fit them into financial objectives and to reduce the raw materials inventory and improve the mean time of payments. They also need to use Internet as a communication channel and elaborate a control report for each produced good. A control for the raw materials is also needed and to obtain information about production technologies in the industry and evaluate the likelihood of investing on them

Alborada Graphics, they operate in the arts and graphs and offset activity. In the project, they do not show any priority. They are searching for a generic advice. They offer as the main tools for the analysis, the evaluation of their functional areas and Porter's five forces. In the diagnosis realised they present high costs of production for a mature industry and a low investment in modern technology. There is a lack of attention to the competence in prices, which is an actual and future trend in the industry, there are problems in the cash flow caused by a time unfit between different mean periods of payment and purchasing. As main recommendations the working group suggest the firm to be prepared to future problems in the transmission of property or the needed changes in the transmission of power. To look for equilibrium in the problem of cash-flows and take care of the assurance in the quality of products and services offered. To incentive people towards the loyalty to the firm and promote the co-operation with competitors.

E-Tridente, they design and produce stands for different events. They offer an integral service to customers. There are 23 employees working in the firm. They recognise as a main problem an excess of power of providers in the firm. There are lots of communication problems amongst hierarchical lines. Too much informal relationships have been generated in the last years. The study of functional areas and an industry analysis in mainly applied. In the diagnosis realised this mains circumstances have been identified, there are too many hierarchical levels that provide problems in the communication system amongst different areas. Different groups of people are looking for different interests and are also sharing different values. There is a unique fabric for the production of products. Many different employees' profiles are working in there. Marketing performs other activities different from their core competence. There is not one specific area for planning the training needs, motivation, etc. Amongst the main recommendations we can emphasise to reduce the excess of power of providers, to increase the number of co-operation agreements with them and think about a less hierarchical structure.

Técnicas Mecánicas Normalizadas, (TMN), they design, manufacture and build metallic furniture (racks) for electronic equipments at a national level. As the main problem, they posses a low degree in the normalisation of working processes. There is some duplicity in the power in different decision levels that can be the origin for future organisational problems. The analysis of the different functional areas and the analysis of models of growth have been implemented. We have found a low formalisation of the work processes, a strange decentralisation of power, difficulty when evaluating a proper way for growing; they are not fully exploiting their ERP which has been implemented two years ago. As main recommendation we suggest the company to perform a 
normalisation of the work processes, to create rules that define in clear way functions, tasks and responsibilities.

TAM Group. It offers an aeronautic modern technology, defence, transport and big installations. They want to implement an ERP. They are trying to select the tool and need pieces of advice in this concrete issue. An analysis of the advantages and disadvantages of the ERPs systems and a personalisation in the analysis to the concrete circumstances of the company has been performed. They are working with a special system developed for them. Although they feel happy with the benefits from this system, they want to analyse the promised results of keeping a more standardised tool. As main recommendations we can stress to pay a special attention to the degree of adaptation to the needs of the company, take care of the post-selling and maintenance of the software. To pay a special attention on the human team that will be taking part in the project (the acquisition of the ERP licenses, the ERP maintenance, the acquisition of the hardware, consultancy services), try to avoid the resistance to the change of potential and real users.

Turbaflor, S.L., It is dedicated to the warehousing and distribution of garden products in the centre of Spain. It is a family firm. There are only 5 employees working on it. They are mainly having family problems with the continuity of the firm. They need to search for new substitutive products since they present a small size in comparison to customers and providers. An industry and a Porter's five forces analysis have been realised. They operate in a mature industry. They have a threat of integration with providers and they have a high power of negotiation with customers and providers. The main recommendations are to be specialised in customers of a high value added. To diversify their activity by looking for tasks to reduce the risk of losing their main provider and to improve the brand image by promoting better communication campaigns and their web page. By describing the products and offering possibilities to potential customers

PAL Electricity, their main activity is providing electric facilities. There are 3 employees working in there. As their main problem, they posses a strategic orientation too centred in the short term. What they consider more important is to deal with aspects referred to motivation and the employees' involvement. An analysis of the functional areas has been performed. They occupy a good position in the market. There is an excess of activities in the day to day work. For this previous reason, it is difficult to plan the expansion of the business in the mean and long term. It is a moment to decide if it is worth to grow or to keep the same size. A lack in the planning could damage their positive image in the market. The organisational structure fits well with firm's size and age. Amongst the main recommendations we suggest to professionalize the operational management in the firm. Every profile must have responsibilities in specific tasks. It is of importance the specific training in leadership and the motivation for specific managerial positions. To implement a system for the control of the quality according to the rule UNE-ENISO 9001:2000 and the design of a strategic plan in two years for the future firm growth.

Hidrocombus, SAU, They are dedicated to the treatment of water by using chemical elements. Their main problem is that they have lots of variety in the employee's professional profiles. They show a special interest for continuous training and there is an absence of the needed telecommunication infrastructures and the collection of surplus in the offices. The main tools for the analysis have been the Porter's five forces, in the diagnosis realised we have found that the providers exercise an excess of power for the company. The seasonal demand makes it difficult the management of the productive activity the progressive fragmentation in the industry can reduce the level of income, customer's loyalty and increase the competency rat. Interest in the entrance of new activities, but at a competitive level the strategy for differentiation is an appropriate one. There is also absence of enough telecommunication infrastructures and the collection of extras in the firms' offices. As main recommendations we suggest to establish co-operation agreements to reduce the excess of negotiation power coming from providers. To think about an organisational structure more formal and complex and the possible creation of an area of $\mathrm{R}+\mathrm{D}$ for the coordina- 
tion of research activities. To widen the different uses for the web, and to use this tool as marketing instrument of a reduced cost.

Castillo, Consultancy services for Properties, They own 62 offices in all Spain. They are worried about the future firm growth. They accept they have a lack of resources. The CEO needs to spend more time in the Business Strategic Management. An analysis of the functional areas has been offered. There is a lack in the employee's specialization. Nobody can be replaced and each customer has a unique relationship with only one firm's employee. The manager is obliged to a continuous surveillance of the firm's activities. He considers it is needed to trespass part of that responsibility to other persons in the firm. We have suggested to promote one only person to be in charged of the attention to the public. A classification of the firm's main problems must be considered for establishing rules or procedures for problem solving. The firm could elaborate an operations leaflet with a detail on main procedures and tasks ended for each activity

Valverauto. They manufacture special devices for driving schools, disabled people. It is a family mature firm in the market. They main problem is that there is a considerable separation of functions. The productive processes are apart from the administrative and financial ones. The analysis of Porter's five forces and SWOT analysis has been implemented. In the diagnosis realised we can stress how there are many mistakes in the financial accounts. There are some deficits in the management of the human resources and they do not have a clear policy of incentives and employee training. As main recommendations there is a need for the redesign in the target of market. They need to look for and grow in the areas where their distinctive competencies are clear, to invest in image and to follow a strategy for market penetration and to study the possibility of incorporate electronic production to analyse the possibility of using based activity costs

\section{Conclusions}

The society is requiring each day more that the research developed in the university produces a direct effect in the creation of value in the economy, in the countries; and so on. This implies a transfer of research results and technology from the university to the different interested business areas.

The relation amongst university and firms can be favoured if it takes into account the help and the tools they can interchange. This is the path that the different units for technological transfer are following up to now. At the same time, these units must investigate about the demands of the productive public sector (transfer oriented to the market) and to design and implement mechanisms for the adjustment of supply and demand.

In this Project, "Technological diagnosis for Firms", we have tried to develop business consultancy in a group of 15 firms established in the south of Madrid, next to the University Campus. The project has been implemented by researchers from the Business Administration Area in the Rey Juan Carlos University in Madrid, Spain. There have been fifteen participant firms. 6 teams of researchers formed by 2, 3, or 4 different members have developed the work. A group of diagnosis and propositions of improvement have been realised in the mentioned group of firms. Different methodologies of strategic and organisational analysis have been used.

Generally speaking, we have found two different types of firms,

$\checkmark$ Those that have informed the team of a concrete problem they have. This kind of consultancy has been oriented towards the solution to that specific problem. An example could be Aeronautic Techniques in Madrid (they have a specific orientation to the process or implementation of the SAP software) or Castillo Administrations (they have been offered specific recommendations of work profiles and oriented in a change of work profiles). 
Another group is formed by those firms that have not mentioned any special problem. In these cases the firm has demanded an analysis and recommendations about its general situation (processes realised, competence threats and strengths, possibilities of growing, etc.)

The different consultant groups have mentioned some problems when dealing with the work. The firms did not have too much time to think about their problems and less time to transmit them. The service has been directly offered by the office of transfer in the university and many of them have perceived it more as an experiment than as a reality. The researcher did not have information about the firms until the moment of start.

Finally, and as an attempt to find out some kind of feedback coming from the firms, we have asked the participants about the results of their experience. We have mainly oriented this survey towards the usefulness and final outcomes of the offered service.

They seem to feel quite satisfied in the quality and the personal attention in the service offered by the consultancy group.

They specially emphasise as positive points the friendship in the service and the clarity in the methodology used. They feel quite satisfied with the time spent in obtaining the final recommendations.

They also seem to appreciate the way time has been managed in the whole process. They feel unsatisfied with the information provided before the work has been developed in their firm. In general, they consider that some more time is needed for the negotiation of the firm and the consultancy team when fixing the main objectives for the project.

However, in some cases, they consider the recommendations in the final report should have been more personalised to their situation. In some cases they have required the same staff to promote some training actions in their firm.

\section{References}

Bukh, P.N. (2003). E*Know Net Final Report WP3. The new research agenda. Mimeo.

Cobbenhaguen, J. (2000). Successful innovation. Cheltenhan: Edward Eldgar

Chaminade, C. (2002). Policy options to promote innovation in SME's through the management of intangibles: best practices and its application to the Spanish Case. Research Proposal. Comunidad de Madrid

Dosi, G., \& Marsili, O. (1995). Learning, market selection and the evolution of industrial structures. Small Business Economics, 7.

Johanson, U.; Martensson, M, \& Skoog, M. (2001). Mobilising change through the management control of intangibles. Accounting, Organization and Society, 7/8, 715-733.

Utterback, J.; \& Abernathy, W. (1975). A dynamic model of process and product innovation. Omega, 3(6).

Winter, S.G. (1984). Schumpeterian competition in alternative technological regimes. Journal of Economic Behavior \& Organization, 5. 


\section{Biographies}

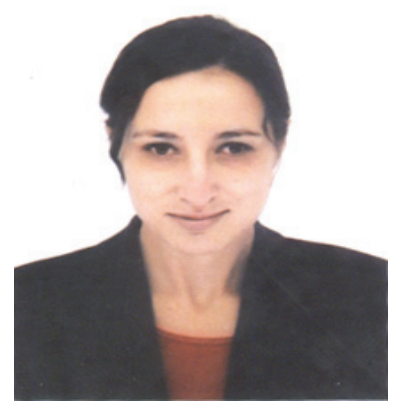

Carmen de Pablos is a Professor in the Business Administration Area at the Rey Juan Carlos University in Madrid, Spain from 1994. She is specialised in the impact of information technologies over organisational systems where she develops main research. She has presented communications in different international venues and has published in specialised journals. She has also worked as a consultant in the area of IS management at Primma Consulting.

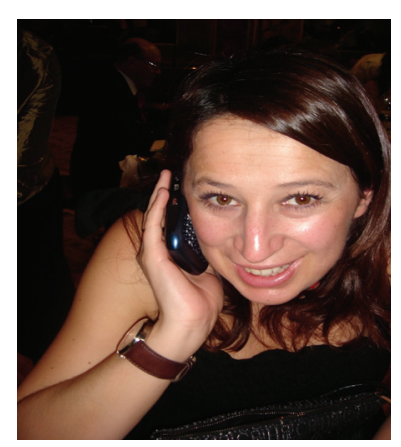

Mónica de Pablos is an Associate Professor in the Business Administration Area at the Rey Juan Carlos University in Madrid, Spain from 2001. She is teaching and doing research in the impact of new technologies in Organizations, specially in the area of ERPs and CRMs. She is also the CIO for the InSitu Group in Spain. 